\title{
Comparative Evaluation of Antimicrobial Efficacy of Three Different Intracanal Medicaments against Candida albicans: An In Vitro Study
}

\author{
Jambai S Sivakumar ${ }^{1}$, Ravi Vaiyapuri ${ }^{2}$, Sasmitha Chandrasekaran ${ }^{3}$, Andamuthu Sivakumar $^{4}$, Anjaneya Shiva Prasad ${ }^{5}$,
} Chittrarasu Mathimaraiselvan ${ }^{6}$

\begin{abstract}
Aim and objective: To evaluate and compare the antimicrobial efficacy of three different intracanal medicaments against Candida albicans by measuring the colony-forming units (CFU) at different time periods.

Materials and methods: Ninety premolar teeth extracted from mandible for orthodontic reasons were collected. The teeth in the experimental groups were decoronated to a standardized length. Canal patency was determined. Cleaning and shaping of the canals were done. Fungal colonies were suspended in $5 \mathrm{~mL}$ of Sabouraud Dextrose Broth (SDB) after being isolated for a day. Ten milliliters of fungal suspension of 0.5 McFarland solution was moved into each canal of the laminar flow hood under sterile conditions. Then, the teeth were divided into three investigational groups $(n=30)$ at random as well as subjected to the following intracanal medicaments: $\mathrm{G} 1-\mathrm{Ca}(\mathrm{OH})_{2}, \mathrm{G} 2-\mathrm{Leder}$ mix paste, $\mathrm{G} 3-$ silver nanoparticles (SNP). The teeth were then put in sterile well plates, and they were secured with multiple layers of paraffin. After loading the various intracanal medicaments, all groups were redivided haphazardly into three uniform subgroups $(n=10)$ and then incubated for different time periods at $37^{\circ} \mathrm{C}$ temperature and $100 \%$ humidity.

On SDB agar, a $0.1 \mathrm{~mL}$ aliquot of the microbial suspension was plated, respectively. After 24 hours, 7 , and 14 days of the incubation period, the number of CFU was assessed with a light microscope $(400 \times)$ and recorded for groups 1, 2, and 3, respectively.

Results: There was a notable dissimilarity between the groups 1,2 , and $3(p<0.01)$. Group 3 was associated with a decreased amount of CFU at all three different meantime.

Conclusion: SNP alone was significantly better in its antimicrobial efficacy against C. albicans over the period of 24 hours, 7 days, and 14 days. Keywords: Antimicrobial, Candida albicans, Colony-forming units, Silver nanoparticles. Journal of Operative Dentistry and Endodontics (2020): 10.5005/jp-journals-10047-0095
\end{abstract}

\section{INTRODUCTION}

The major objective of root canal treatment is to attain the decontamination of root canals by the eradication of microbes and prevention of recontamination. In spite of the fact that mechanical instrumentation can decrease microbial colonization, effective decontamination of organisms cannot be attained without the use of antimicrobial root canal medicaments. ${ }^{1}$ An important consideration in endodontic treatment is the elimination of microorganisms, including fungi, from the complex three-dimensional root canal system. ${ }^{2}$ Intracanal medicaments are used against endodontic microbial flora. They are proven to be effective against microbes that survive instrumentation and irrigation. ${ }^{3}$ The predominant fungus in the oral cavity is the Candida albicans, and it is a dimorphic fungus that survives in various morphological forms. The prevalence of C. albicans in the oral cavity is $30-40 \%$ in healthy adults and $95 \%$ in patients with human deficiency virus. ${ }^{4} \mathrm{C}$. albicans is a resistant pathogen in the root canal with an incidence of $6-18 \% .^{5}$

\section{Materials and Methods}

A detailed protocol explaining the purpose and procedures of the study was submitted to the Institutional Ethics Committee, and ethical clearance was obtained. Ninety premolar teeth extracted from the mandible for orthodontic reasons were collected. Periapical radiographs were taken to confirm the lack of calcification, internal resorption, or an extra root canal.

\footnotetext{
${ }^{1-6}$ Department of Conservative Dentistry and Endodontics, Vivekanandha Dental College for Women, Tiruchengode, Tamil Nadu, India

Corresponding Author: Sasmitha Chandrasekaran, Department of Conservative Dentistry and Endodontics, Vivekanandha Dental College for Women, Tiruchengode, Tamil Nadu, India, Phone: +91 9865588080, e-mail: sasmithaachandrasekaran@gmail.com

How to cite this article: Sivakumar JSK, Vaiyapuri R, Chandrasekaran S, et al. Comparative Evaluation of Antimicrobial Efficacy of Three Different Intracanal Medicaments against Candida albicans: An In Vitro Study. J Oper Dent Endod 2020;5(2):79-82.

Source of support: Nil

Conflict of interest: None
}

Methodology planned was through the following steps:

- Preparation of teeth specimen

- Microbiological procedure (contamination with C. albicans)

- Sample distribution (antimicrobial activity of medicaments)

- Microbiological sampling

\section{Preparation of Teeth Specimen}

The teeth in the experimental groups were decoronated to a standardized length of $15 \mathrm{~mm}$ using a diamond disc with water coolant, followed by the determination of canal patency with size 
$15 \mathrm{~K}$-file, and confirmed by taking intraoral periapical radiograph. Cleaning and shaping of the canals were done with ProTaper Universal rotary file system till size $\mathrm{F} 3$ by crown-down technique using X-smart endomotor and hand piece to $1 \mathrm{~mm}$ short of the root apex. Irrigation was performed with $5.25 \%$ sodium hypochlorite solution with size 27-G open-ended standard tip needle between each file usage and finally irrigated with $17 \%$ ethylenediaminetetraacetic acid (EDTA). The prepared root canals were dried with absorbent paper points. The outer surface of the specimens was covered with two layers of varnish, and the apex was secured with self-cure glass ionomer cement. The teeth were then transferred into $2 \mathrm{~mL}$ microtubes and autoclaved at $121^{\circ} \mathrm{C}$ under $15 \mathrm{lbs}$ pressure for 15 minutes. ${ }^{6}$

\section{Microbiological Procedure (Contamination with C. albicans)}

Clinical isolates of $C$. albicans were used as a test microorganism (Fig. 1). After being isolated for 24 hours, fungal colonies were suspended in $5 \mathrm{~mL}$ of Sabouraud Dextrose Broth (SDB) and incubated at $37^{\circ} \mathrm{C}$ for 4 hours. The 90 root specimens were transferred into sterile cell culture well plates (each plate having 24 wells) under sterile conditions. Roots were mounted in the well plates containing $2 \%$ sterile agar media that was allowed to solidify so that the root specimens can be stabilized. Each canal of the laminar flow hood received $10 \mathrm{~mL}$ of $0.5 \mathrm{McF}$ arland solution of the fungal suspension under sterile conditions using micropipettes (Fig. 2). After injection, each specimen corresponding to the intracanal medicament groups was submerged in SDB, and the tubes were anaerobically incubated at $37^{\circ} \mathrm{C}$ for 24 hours. Then, the cell culture plates were recapped and sealed with multiple layers of paraffin and incubated for 21 days at $37^{\circ} \mathrm{C}$ (Fig. 3). Every alternate day, $10 \mathrm{~mL}$ of fresh SDB was added to ensure the viability of the fungi. ${ }^{7}$

\section{Sample Distribution \\ (Antimicrobial Activity of Medicaments)}

The medium in the well plates was aseptically aspirated at the end of the incubation period. The teeth were then divided into three experimental groups $(n=30)$ at random and subjected to the following intracanal medicaments:

- Group 1-0.1 g Ca(OH) $)_{2}$ per $1 \mathrm{~mL}$ of sterile water

- Group 2-0.1 g Leder mix paste

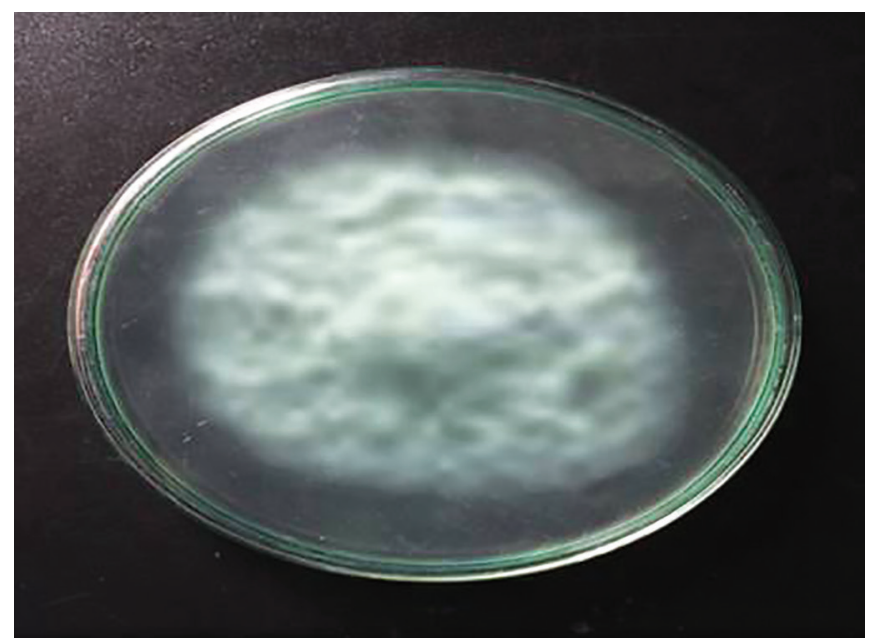

Fig. 1: Clinical isolates of C. albicans (ATCC-10231) suspended in $5 \mathrm{~mL}$ of SDB used as test microorganism
- Group 3-100 ppm of preformed SNP of $10 \mathrm{~nm}$ size per $1 \mathrm{~mL}$ of sterile water.

The medications were inserted into the canal with the aid of $3 \mathrm{~mL}$ syringe and 27 gauge needle under aseptic conditions in all experimental groups until the canals are totally full. Sterile aluminum foil was used to cover the canal orifices. The teeth were then put in sterile well plates, and several layers of paraffin were used to seal them. Following the loading of the various medicaments, all groups were randomly redivided into three uniform subgroups $(n=10)$ and then incubated for varying periods of time, i.e., 24 hours, 7 , and 14 days with a temperature of $37^{\circ} \mathrm{C}$ and a humidity of $100 \%$.

\section{Microbiological Sampling}

Microbiological samples were obtained by inserting a sterile \#30 paper point, placing it into the canal for 60 seconds, and then transferring this paper point into the micro test tube containing $1 \mathrm{~mL}$ of physiological saline solution and vortex shaking it for 30 seconds.

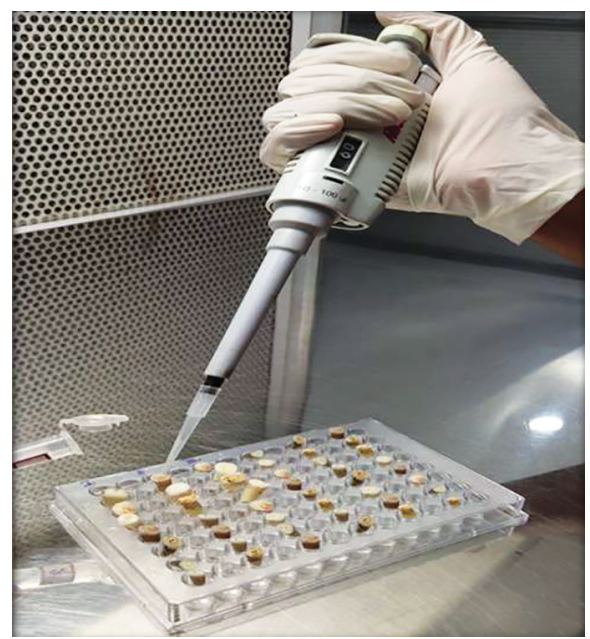

Fig. 2: Ten milliliters of 0.5 McFarland solution of the fungal suspension was transferred into each canal

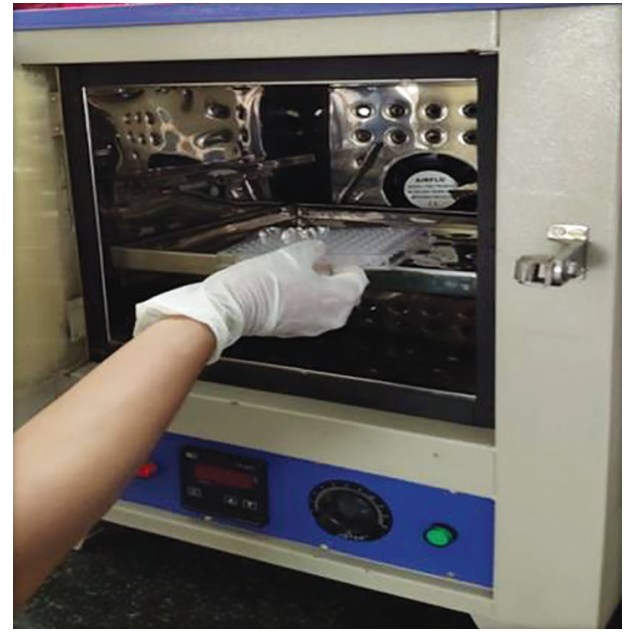

Fig. 3: Each specimen corresponding to the intracanal medicament groups was submerged in SDB, and the tubes were incubated anaerobically at $37^{\circ} \mathrm{C}$ for 24 hours 
After 24 hours, 7, and 14 days of the incubation period, the number of colony forming units was measured with a light microscope under $400 \times$ magnification and recorded for groups 1, 2, and 3, respectively. ${ }^{8}$

\section{Statistical Analysis}

The obtained results were statistically analyzed using SPSS version 18 , and the study parameters among the groups at 24 hours, 7 , and 14 days were compared using KruskalWallis one way analysis of variance (ANOVA); the statistical significance level was set at $p<0.01$.

\section{Results}

Descriptive statistics for three groups at different time intervals are given in Table 1. Highly significant value $(<0.01)$ was found in different intracanal medicament group's antimicrobial efficacy against C. albicans after 24 hours, 7 days, and 14 days. Significantly reduced number of microbiological colonies were observed on the experimental plates in group 3 (SNP) compared to group 1 $\left(\mathrm{Ca}(\mathrm{OH})_{2}\right)$ and group 2 (Leder mix) at all three different time intervals. Comparison among all the three groups at different time intervals was given in Table 2, i.e., group $3<$ group $2<$ group 1.

Table 1: Descriptive statistics of three groups at a different time interval

\begin{tabular}{llrrrr}
\hline Time interval & Groups & $N$ & Mean $(\mathrm{CFU} / \mathrm{mL})$ & Std. deviation & Std. error \\
\hline After & Group 1 & 10 & 24.73 & 0.03 & 0.01 \\
24 hours & Group 2 & 10 & 2.16 & 0.01 & 0.00 \\
& Group 3 & 10 & 0.97 & 0.01 & 0.00 \\
& Total & 30 & 9.29 & 11.12 & 2.03 \\
After 7 days & Group 1 & 10 & 25.15 & 0.01 & 0.00 \\
& Group 2 & 10 & 3.22 & 0.04 & 0.01 \\
& Group 3 & 10 & 1.25 & 0.02 & 0.01 \\
After & Total & 30 & 9.87 & 11.02 & 2.01 \\
14 days & Group 1 & 10 & 18.73 & 0.02 & 0.01 \\
& Group 2 & 10 & 1.26 & 0.01 & 0.00 \\
& Group 3 & 10 & 0.15 & 0.01 & 0.00 \\
& Total & 30 & 6.71 & 8.66 & 1.58 \\
\hline
\end{tabular}

Table 2: Comparison among three groups at a different time interval

\begin{tabular}{|c|c|c|c|c|c|c|}
\hline & & $\begin{array}{l}\text { Sum of } \\
\text { squares }\end{array}$ & $D f$ & $\begin{array}{l}\text { Mean } \\
\text { square }\end{array}$ & $F^{\#}$ & Sig. \\
\hline \multirow[t]{3}{*}{$\begin{array}{l}\text { After } \\
24 \text { hours }\end{array}$} & $\begin{array}{l}\text { Between } \\
\text { groups }\end{array}$ & 3585.46 & 2 & 1792.73 & 5888521.52 & $0.000^{*}$ \\
\hline & $\begin{array}{l}\text { Within } \\
\text { groups }\end{array}$ & 0.01 & 27 & 0.00 & & \\
\hline & Total & 3585.46 & 29 & & & \\
\hline \multirow[t]{3}{*}{$\begin{array}{l}\text { After } \\
7 \text { days }\end{array}$} & $\begin{array}{l}\text { Between } \\
\text { groups }\end{array}$ & 3520.28 & 2 & 1760.14 & 2228024.99 & $0.000^{*}$ \\
\hline & $\begin{array}{l}\text { Within } \\
\text { groups }\end{array}$ & 0.02 & 27 & 0.00 & & \\
\hline & Total & 3520.30 & 29 & & & \\
\hline \multirow[t]{3}{*}{$\begin{array}{l}\text { After } \\
14 \text { days }\end{array}$} & $\begin{array}{l}\text { Between } \\
\text { groups }\end{array}$ & 2173.26 & 2 & 1086.63 & 5577751.90 & $0.000^{*}$ \\
\hline & $\begin{array}{l}\text { Within } \\
\text { groups }\end{array}$ & 0.01 & 27 & 0.00 & & \\
\hline & Total & 2173.26 & 29 & & & \\
\hline
\end{tabular}

*Highly significant $(p<0.01)$, ${ }^{\#}$ One-way ANOVA test

\section{Discussion}

The nonspecific eradication of intraradicular microorganisms is the foundation during root canal treatment. While several studies have found that inter-appointment intracanal medication is effective in killing microorganisms, some clinicians prefer single-visit root canal therapy. Intracanal medicaments work within the dentinal tubules and at the apical end of the root canal, in addition to the root canal lumen.

The most common fungi cultured from failed root canal treatments are C. albicans. Dentin can be used as a source of nutrition by $C$. albicans because of its collagenolytic activity. This increases its virulence and encourages colonization in the root canal. ${ }^{9}$ The instrumentation method was same for all of the groups in this analysis. The canals were uniformly instrumented $1 \mathrm{~mm}$ shorter than the tip of the apex to ensure proper cleaning of the apical third. EDTA was used to remove the smear layer. By irreversibly oxidizing the hydrosulfuric groups of basic enzymes, sodium hypochlorite disrupts metabolic functions in microorganisms and thus serves as an important root canal irrigant. Until inoculating the root canals with C. albicans, $5.25 \%$ sodium hypochlorite was used to make them sterile. And $7-18 \%$ cases of persistent apical periodontitis have the prominence of $C$. albicans. Studies have shown that Candida can tolerate even higher alkalinity compared to Enterococcus faecalis. It is reported to be resistant against calcium hydroxide, ${ }^{10}$ which is evident in this study, also showing maximum colonies of the species in all three different time intervals. Waltimo et al. stated that calcium hydroxide is the most widely used and researched root canal medicament. Calcium hydroxide has been evaluated since its introduction for its alkaline $\mathrm{pH}$, ionic activity, diffusion through dentinal tubules, influence on apical microleakage, and placement within the root canal. Calcium hydroxide is traditionally prepared by mixing the powder with a liquid and injecting it into the root canal with a needle, root canal instrument, GP, or paper points. To make a paste with $\mathrm{Ca}(\mathrm{OH})_{2}$ powder, use sterile water or glycerin as a vehicle. ${ }^{11}$ Calcium and hydroxyl ions should be released gradually and slowly by the ideal vehicle.

Hence, intracanal medicament propelled researchers to introduce nanoparticles in the field of endodontics. SNP (AgNP) possess bactericidal activities since they have the ability to bind with proteins and enzymes, thereby interfering with the integrity of the bacterial cell wall. ${ }^{12}$ Roe et al. have shown that coating of SNP as an antibiofilm agent over catheters increased its potency against bacteria Escherichia coli, Staphylococcus aureus, and the fungi C. albicans. ${ }^{13}$ In the current study, AgNPs of size $10 \mathrm{~nm}$ was used since smaller particles yield greater surface area and heightened antimicrobial properties. Compared to pure silver nitrate, the antimicrobial effectiveness of silver is increased when incorporated in the copolymer. Silver inactivation by nutrient broth or by the microorganisms themselves has been suggested as a cause for this phenomenon. ${ }^{14}$

The antimicrobial properties of silver have long been established. The use of silver or silver salts as key components to regulate microbial proliferation has grown in popularity in recent years. They are actually used in a wide range of products that we use on a regular basis. ${ }^{15}$ Medicaments such as Leder mix are able to penetrate the periodontal and periapical tissues by diffusing them into dentinal tubules and cementum. According to Abbott et al., the dentinal tubules were the primary route for active components to reach the periradicular tissues, while the apical foramen was not as essential as a means of supply. ${ }^{16}$ 
In root canal therapy, medicaments that combine antibiotics and corticosteroid elements are highly effective. The corticosteroid component reduces periapical inflammation and pain in patient who complains of severe tenderness to percussion after canal instrumentation, while antibiotics have antimicrobial properties. In different parts of the world, an antibiotic/corticosteroid combination (Leder mix) has been widely used as a vital pulp dressing and a root canal medicament in paste and cement types. This study has reported that a significantly reduced number of microbiological colonies were observed on the experimental plates in group 3 (SNP) compared to group $1\left(\mathrm{Ca}(\mathrm{OH})_{2}\right)$ and group 2 (Leder mix) at all the three different time intervals.

\section{Conclusion}

Within the study limitations, all three groups were considered to have antimicrobial properties, but the SNP alone was significantly better in its antimicrobial efficacy against $C$. albicans over the period of 24 hours, 7 days, and 14 days. SNPs in combination with other medicaments will show significantly better efficacy than it is used alone. More studies are required to validate this approach.

\section{References}

1. El Karim I, Kennedy J, Hussey D. The antimicrobial effects of root canal irrigation and medication. Oral Surg Oral Med Oral Pathol Oral Radiol Endod 2007;103(4):560-569. DOI: 10.1016/j.tripleo.2006.10.004.

2. Kumar J, Sharma R, Sharma M, et al. Presence of Candida albicans in root canals of teeth with apical periodontitis and evaluation of their possible role in failure of endodontic treatment. J Int Oral Health 2015;7(2):42-45. PMID: 25859106.

3. Haapasalo M, Udnaes T, Endal U. Persistent, recurrent and acquired infection of the root canal system post treatment. Endod Top 2003;6(1):29-56. DOI: 10.1111/j.1601-1546.2003.00041.x.

4. Al-Nazhan S, Al-Sulaiman A, Al-Rasheed F, et al. Microorganism penetration in dentinal tubules of instrumented and retreated root canal walls in vitro SEM study. Restor Dent Endod 2014;39(4):258-264. DOI: 10.5395/rde.2014.39.4.258.
5. Waltimo TM, Sirén EK, Orstavik D, et al. Susceptibility of oral candida species to calcium hydroxide in vitro. Int Endod J 1999;32(2):94-98. DOI: 10.1046/j.1365-2591.1999.00195.x.

6. Western JS, Dicksit DD. A systematic review of randomized controlled trials on sterilization methods of extracted human teeth. J Conserv Dent 2016;19(4):343. DOI: 10.4103/0972-0707.186457.

7. Chandra A, Yadav RK, Shakya VK, et al. Antimicrobial efficacy of silver nanoparticles with and without different antimicrobial agents against Enterococcus faecalis and Candida albicans. Dent Hypotheses 2017;8(4):94-99. DOI: 10.4103/denthyp.denthyp_17_17.

8. Babu B, Nair RS, Angelo JM, et al. Evaluation of efficacy of chitosansilver nanocomposite on Candida albicans when compared to three different antifungal agents in combination with standard irrigation protocol: An ex vivo study. Saudi Endod J 2017;7(2):87-91. DOI: 10.4103/1658-5984.205124.

9. Waltimo TMT, Siren EK, Torkko HLK, et al. Fungi in therapyresistant apical periodontitis. Int Endod J 1997;30(2):96-101. DOI: 10.1046/j.1365-2591.1997.00058.x.

10. Waltimo TM, Haapasalo M, Zehnder M, et al. Clinical aspects related to endodontic yeast infections. Endod Top 2004;9(1):66-78. DOI: 10.1111/j.1601-1546.2004.00086.x.

11. Pezelj-Ribaric S, Brekalo I, Abram M, et al. Influence of calcium hydroxide root-canal sealer on microbial growth in vitro. Folia Microbiol (Praha) 2002;47(4):458-460. DOI: 10.1007/BF02818709.

12. Schreurs WJ, Rosenberg $\mathrm{H}$. Effect of silver ions on transport and retention of phosphate by Escherichia coli. J Bacteriol 1982;152(1): 7-13. PMID: 6749823.

13. Roe D, Karandikar B, BonnSavage N, et al. Antimicrobial surface functionalization of plastic catheters by silver nanoparticles. J Antimicrob Chemother 2008;61(4):869-876. DOI: 10.1093/jac/dkn034.

14. Martinez-Abad A, Lagaron JM, Ocio MJ. Development and characterization of silver-based antimicrobial ethylene-vinyl alcohol copolymer (EVOH) films for food-packaging applications. J Agric Food Chem 2012;60(21):5350-5359. DOI: 10.1021/jf300334z.

15. Bouwmeester H, Dekkers S, Noordam MY, et al. Review of health safety aspects of nanotechnologies in food production. Regul Toxicol Pharmacol 2009;53(1):52-62. DOI: 10.1016/j.yrtph.2008.10.008.

16. Abbott PV. Medicaments: aids to success in endodontics. Part 1. A review of the literature. Aust Dent J 1990;35(5):438-448. DOI: 10.1111/j.1834-7819.1990.tb05427.x. 